\title{
Public Perception and Attitude toward Community Pharmacists in Saudi Arabia
}

\author{
Omar A. Almohammed ${ }^{a}$ Sary Alsanea ${ }^{b}$ \\ aDepartment of Clinical Pharmacy, College of Pharmacy, King Saud University, Riyadh, Kingdom of Saudi Arabia; \\ ${ }^{b}$ Department of Pharmacology and Toxicology, College of Pharmacy, King Saud University, Riyadh, Kingdom of \\ Saudi Arabia
}

\section{Keywords}

Pharmacists · Community pharmacy · Perception ·

Attitude $\cdot$ Satisfaction

\begin{abstract}
Background: The Saudi healthcare system is undergoing a major transformation, and pharmacists will assume more responsibilities in providing healthcare services. The current study aims to determine the current perception and attitude of the public toward pharmacists, as well as the public satisfaction with pharmacists' practices and services in the community pharmacy setting. Methods: A cross-sectional, online questionnaire-based study was conducted between February and April 2019 and included adult participants ( $\geq 18$ years) who could read and complete an Arabic online survey. $x^{2}$ and correlation tests were used to investigate differences in perception and attitude toward community pharmacists based on study population demographics and characteristics and assess the association between public perception and attitude. Statistical analysis was conducted using SAS software, version 9.4. Results: A total of 387 participants completed the survey. The overall Saudi public's perception and attitude toward community pharmacists
\end{abstract}

karger@karger.com www.karger.com/sjh

Karger!
C 2021 The Author(s)

Published by S. Karger AG, Basel

This is an Open Access article licensed under the Creative Commons Attribution-NonCommercial-4.0 International License (CC BY-NC) (http://www.karger.com/Services/OpenAccessLicense), applicable to the online version of the article only. Usage and distribution for commercial purposes requires written permission. were positive in the study population, scoring $81.4 \%$ for perception and $69.8 \%$ for attitude, with female participants having a more favorable perception of community pharmacists than male participants ( 89.3 vs. $77.7 \%, p<0.01)$. A strong and positive correlation between public perception and attitude was recognized in the study $(r=0.71, p<0.01)$. The participants were found to be mostly satisfied with pharmacists' commitment and communication skills, but not, however, with the level of pharmaceutical care services provided. Conclusion: The current positive perception and attitude toward community pharmacists among the Saudi public create an opportunity for pharmacists to assume expanded roles as healthcare providers. However, their pharmaceutical care skills should be improved in order to gain their patients' trust and provide them with valuable services.

(c) 2021 The Author(s)
Published by S. Karger AG, Basel

\section{Introduction}

The Saudi healthcare system is currently undergoing major transformation, and pharmacists in the community pharmacy setting can play a major role in this transformation as they will be able to assume more responsi- 
bilities in providing healthcare services to their consumers. Recent changes to the rules and regulations governing the community pharmacies' work and responsibilities have allowed pharmacists to provide certain clinical services that they were previously not authorized to perform, such as administering vaccinations, training patients on the use of medical devices, and conducting medication therapy management [1]. On the other hand, the overall health literacy levels among the Saudi population and their awareness about health-related subjects have clearly improved over the years, even though it has yet to reach an optimal level $[2,3]$. This has created an increasing demand for healthcare providers, including community pharmacists, to provide knowledge, services, and recommendations of the highest level to their patients.

Moreover, the relationship between physicians and patients is known to affect the patient's health outcomes and overall satisfaction with the healthcare service [4], and the same is assumed for pharmacists and their relationships with patients. For the public to enquire about health-related subjects and accept medical recommendations from healthcare providers, including pharmacists, a positive perception of and attitude toward them are necessary. A cross-sectional study was conducted to assess the relationship between the public perception of community pharmacists and their willingness to participate in services provided by pharmacists. The study found that many of the patients perceived community pharmacists as healthcare providers, which reflected a positive perception about pharmacists, and further found that this favorable perception positively affected patients' willingness to participate in several pharmacist-provided services [5]. In the United Arab Emirates, a similar cross-sectional study found that approximately half of the participants believed their privacy was not secure when they discussed any health-related issues or a prescription with community pharmacists. Trust was another issue for about $17 \%$ of the participants, who indicated that they trusted their physician more that their pharmacist, and preferred to see their physicians when they needed attention for a medical condition. Added to this, $10 \%$ of the participants saw community pharmacists primarily as business personnel and could not, as a result, be considered legitimate healthcare providers in their view [6]. Moreover, a cross-sectional study from Canada showed that participants were willing to pay for the valued medication management services provided by community pharmacists [7], whereas a study from China showed that the unsatisfactory experience with community pharmacists led to over-the-counter self-medication and avoidance of advices from commu- nity pharmacists [8]. These international studies demonstrate the importance of patients' perception of community pharmacists and satisfaction with pharmacy services and the impact of that on patients and pharmacy practice.

In the Kingdom of Saudi Arabia (KSA), a cross-sectional study was conducted in Riyadh to assess the pharmacists' performance as healthcare providers and the public's satisfaction with services provided by community pharmacists. The study found that about one-third of the participants perceived community pharmacists as dispensers only, while another one-third believed that pharmacists played a major role in their medication compliance. Moreover, about half of the participants acknowledged the role of the pharmacists in addressing medication-related problems and considered pharmacists to be effective members of the healthcare system [9]. In another study, about two-thirds of consumers felt comfortable asking a community pharmacist for medical advice, two-thirds indicated that their pharmacists were willing to provide them with a medical consultation, and less than half felt satisfied with the time dedicated to them from pharmacists in the community setting [10]. These were the only studies that assessed the public perception of or attitude toward community pharmacists in the KSA.

The present study aimed to determine the current perception and attitude of the public toward community pharmacists in the KSA and also aimed to assess public satisfaction with community pharmacists' practices and the professional services they provide. Without the public's positive perception and attitude, community pharmacists may not prove to be significant players in the overall healthcare system.

\section{Material and Methods}

\section{Study Design}

A cross-sectional, survey-based study was conducted to assess the current perception and attitude of the public toward community pharmacists in the KSA. The study included adult participants ( $\geq 18$ years) who could read and complete an online survey in Arabic. The online survey was developed to facilitate data collection from the participants, and WhatsApp ${ }^{\circledR}$ was utilized to facilitate survey distribution to different regions in the KSA.

\section{Questionnaire}

The online questionnaire consisted of 3 main sections with a total of 34 items. Demographics formed the first section and comprised 8 multiple-choice questions relating to age, gender, nationality, marital status, highest educational achievement, average income, educational or work experience, and current job status. The second section consisted of 17 statements in which participants were asked to rate on a Likert scale to evaluate their perception (10
68

Saudi J Health Syst Res 2021;1:67-74 DOI: $10.1159 / 000515207$
Almohammed/Alsanea 
items) and attitude (7 items) toward community pharmacists. The third section consisted of 9 items that reflected the participants' experience with community pharmacists and focused on the public's satisfaction with the community pharmacists' practices and professional services provided to them. The participants were asked to rate their level of agreement with these 9 statements on a Likert scale to identify common points of both approval and criticism from the public about community pharmacists' practices in the KSA. Since Arabic is the official language of the KSA, the questionnaire was constructed and administered in Arabic to facilitate the comprehension of the survey items. The questionnaire items were listed in Arabic and translated into English in the supplementary material.

The questionnaire items were checked for clarity and face validity by 2 independent researchers before the questionnaire was distributed to respondents. Internal reliability of the perception items and attitude items was checked using Cronbach's a statistics. For the 10 public perception items in the questionnaire, 2 items were deleted to achieve acceptable internal reliability among the remaining 8 perception items, with a Cronbach's a of 0.857 . For the 7 public attitude items in the questionnaire, only 1 item was deleted to achieve acceptable internal reliability for the remaining 6 items, with a Cronbach's a of 0.848 .

\section{Data Collection}

Survey participants were recruited using a convenience sampling technique via an invitation letter sent to them through WhatsApp ${ }^{\circledR}$. The use of WhatsApp ${ }^{\circledR}$ among adults in the KSA is very common [11] and was presumed to be an appropriate method of survey distribution in order to reach a diverse convenience sample from different regions in the country, and participants were informed about the purpose of the study in the WhatsApp ${ }^{\circledR}$ invitation letter. The data were collected over a 3-month period between February 1, 2019 and April 30, 2019, using an online survey tool (Microsoft Forms ${ }^{\circledR}$ ), and the obtained data were secured within an encrypted database. The study design and the questionnaire were approved by the Institutional Review Board at King Saud University.

\section{Data Analysis}

The study utilized descriptive statistics to describe the participants' demographics and their perception and attitude toward community pharmacists, whereas inferential statistics were utilized to investigate differences in the perception and attitude toward community pharmacists based on the participants' demographics (using $\chi^{2}$ tests) and the association between the perception and attitude constructs (using Spearman correlation tests). Additionally, the principal component analysis was utilized to investigate principal components in the questionnaire section relating to participants' experience with community pharmacists. The data from responses to the Likert scale items were coded into numbers from 1 to 5 ( 1 , totally disagree to 5 , totally agree) and transformed when necessary (such as in the case of negative statements). The study assumed that $50 \%$ of the population would have a positive perception and attitude toward pharmacists in the community setting; based on that and with a 95\% confidence level and 5\% margin of error, the sample size was calculated to be 385 . An a level of $<0.05$ was used for statistical significance. The data from the questionnaire were coded, checked for accuracy, and then analyzed using SAS software, version 9.4 (SAS Institute Inc., Cary, NC, USA).

Perception and Attitude toward

Community Pharmacists in Saudi
Table 1. Respondent's demographic characteristics

\begin{tabular}{|c|c|}
\hline Characteristic & Frequency, \% \\
\hline \multicolumn{2}{|l|}{ Age, years } \\
\hline $18-25$ & $129(33.3)$ \\
\hline $26-35$ & $96(24.8)$ \\
\hline $36-45$ & $92(23.8)$ \\
\hline $46-60$ & $53(13.7)$ \\
\hline Older than 60 & $17(4.4)$ \\
\hline \multicolumn{2}{|l|}{ Gender } \\
\hline Male & $265(68.5)$ \\
\hline Female & $122(31.5)$ \\
\hline \multicolumn{2}{|l|}{ Nationality } \\
\hline Saudi & $378(97.7)$ \\
\hline Non-Saudi & $9(2.3)$ \\
\hline \multicolumn{2}{|l|}{ Marital status } \\
\hline Married & $234(60.5)$ \\
\hline Single & $153(39.5)$ \\
\hline \multicolumn{2}{|l|}{ Highest level of education } \\
\hline Less than high school & $6(1.6)$ \\
\hline High school & $79(20.4)$ \\
\hline Diploma & $35(9.0)$ \\
\hline Bachelor degree & $201(51.9)$ \\
\hline Master degree or higher & $66(17.1)$ \\
\hline \multicolumn{2}{|l|}{ Education or occupational field } \\
\hline Health & $122(31.5)$ \\
\hline Education & $112(28.9)$ \\
\hline Military & $29(7.5)$ \\
\hline Business or private sector & $28(7.2)$ \\
\hline No previous experience or other & $96(24.8)$ \\
\hline \multicolumn{2}{|l|}{ Average monthly income, SR } \\
\hline Less than 3,000 & $111(28.7)$ \\
\hline $3,000-7,000$ & $46(11.9)$ \\
\hline $7,001-12,000$ & $77(19.9)$ \\
\hline $12,001-18,000$ & $78(20.2)$ \\
\hline $18,001-25,000$ & $27(7.0)$ \\
\hline More than 25,000 & $48(12.4)$ \\
\hline \multicolumn{2}{|l|}{ Job status } \\
\hline Employed & $220(56.8)$ \\
\hline Unemployed & $122(31.5)$ \\
\hline Retired & $45(11.6)$ \\
\hline
\end{tabular}

\section{Results}

A total of 387 participants completed the survey. The majority of the respondents were male $(68.5 \%)$, of relatively young age $(18-35$ years $=58.1 \%)$, and $56.8 \%$ of the respondents were employed. Approximately one-third of the respondents worked in the medical field and 29\% worked in the field of education. The respondents' demographics were summarized in Table 1.

\section{Respondents' Perceptions of Community Pharmacists}

Responses to the 8 final questionnaire items concerning public perception of community pharmacists were 
Table 2. Respondents' perception and attitude toward community pharmacists based on demographic characteristics

\begin{tabular}{|c|c|c|c|c|}
\hline Demographic & $\begin{array}{l}\text { Positive } \\
\text { perception, \% }\end{array}$ & $p$ value & $\begin{array}{l}\text { Positive } \\
\text { attitude, \% }\end{array}$ & $p$ value \\
\hline \multicolumn{5}{|l|}{ Age, years } \\
\hline $18-25$ & 84.5 & \multirow{5}{*}{0.618} & 74.4 & \multirow{5}{*}{0.244} \\
\hline $26-35$ & 82.3 & & 63.5 & \\
\hline $36-45$ & 78.3 & & 71.7 & \\
\hline $46-60$ & 81.1 & & 71.7 & \\
\hline$>60$ & 70.6 & & 52.9 & \\
\hline \multicolumn{5}{|l|}{ Gender } \\
\hline Male & 77.7 & \multirow[b]{2}{*}{$0.004^{*}$} & 67.2 & \multirow{2}{*}{0.097} \\
\hline Female & 89.3 & & 75.4 & \\
\hline \multicolumn{5}{|l|}{ Marital status } \\
\hline Married & 81.6 & \multirow{2}{*}{0.886} & 68.8 & \multirow{2}{*}{0.609} \\
\hline Single & 81.1 & & 71.2 & \\
\hline \multicolumn{5}{|l|}{ Highest level of education } \\
\hline Less than high school & 83.3 & \multirow{5}{*}{0.306} & 100 & \multirow{5}{*}{ na } \\
\hline High school & 82.3 & & 75.9 & \\
\hline Diploma & 77.1 & & 48.6 & \\
\hline Bachelor degree & 84.6 & & 71.6 & \\
\hline Master degree or higher & 72.7 & & 65.2 & \\
\hline \multicolumn{5}{|l|}{ Educational or work field } \\
\hline Health & 81.2 & \multirow{5}{*}{0.703} & 73.8 & \multirow{5}{*}{0.727} \\
\hline Education & 83.0 & & 70.5 & \\
\hline Military & 79.3 & & 65.5 & \\
\hline Business & 71.4 & & 64.3 & \\
\hline No previous experience or other & 83.3 & & 66.7 & \\
\hline \multicolumn{5}{|l|}{ Average monthly income, SR } \\
\hline Less than 3,000 & 89.2 & \multirow{6}{*}{0.068} & 75.7 & \multirow{6}{*}{0.484} \\
\hline $3,000-7,000$ & 87.0 & & 69.6 & \\
\hline $7,001-12,000$ & 74.0 & & 62.3 & \\
\hline $12,001-18,000$ & 79.5 & & 70.5 & \\
\hline $18,001-25,000$ & 74.1 & & 63.0 & \\
\hline More than 25,000 & 77.1 & & 70.8 & \\
\hline \multicolumn{5}{|l|}{ Job status } \\
\hline Employed & 77.3 & \multirow{3}{*}{0.016} & 66.4 & \multirow{3}{*}{0.099} \\
\hline Unemployed & 89.3 & & 77.1 & \\
\hline Retired & 80.0 & & 66.7 & \\
\hline
\end{tabular}

na, not applicable. ${ }^{*} p$ value $<0.05$ is considered statistically significant.

combined together and transformed into 1 cumulative variable. The participants who responded positively to most of these statements were considered to have an overall positive perception about community pharmacists, whereas the remaining participants were considered to have a neutral or negative perception of community pharmacists.

The majority of the respondents $(81.4 \%)$ had an overall positive perception of community pharmacists. The overall positive perception was consistently high across different age-groups, with the lowest being among the group over 60 years of age (70.6\%). The overall positive perception was more common among female than male participants ( 89.3 vs. $77.7 \%, p<0.01$ ). Unemployed participants had more favorable perceptions of community pharmacists than the employed and retired $(p=0.016)$. The overall positive perception was consistent among individuals working in different sectors, with the lowest positive perception rates found among the group working in the business or the private sector $(71.4 \%)$. The respondents' perception of pharmacists in the community setting is summarized in Table 2. 
Table 3. Respondents' satisfaction with community pharmacists' practices and professional services

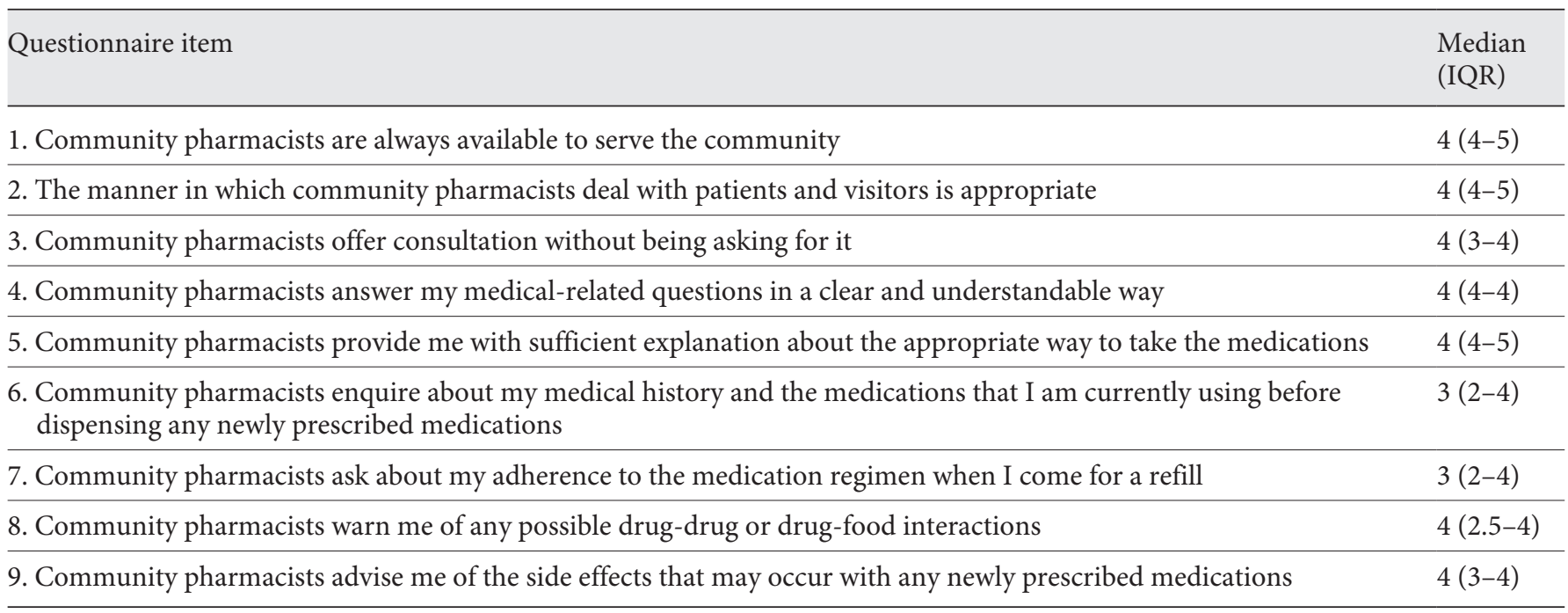

\section{Respondents' Attitude toward Community Pharmacists}

Responses to the 6 final questionnaire items concerning attitude were combined together and transformed into 1 cumulative variable. The participants who responded positively to most of these statements were considered to have an overall positive attitude toward pharmacists, whereas the remaining participants were considered to have a neutral or negative attitude toward community pharmacists.

About two-thirds of the respondents (69.8\%) had an overall positive attitude toward pharmacists working in community pharmacies in the KSA. The overall positive attitude was consistent across different age-groups, with the lowest positive attitude rate being among the group over 60 years of age (52.9\%). The overall positive attitude was more common among female (75.4\%) than male participants (67.2\%), but that did not reach the level of significance. The respondents' attitude toward pharmacists in the community setting is summarized in Table 2.

\section{Relationship between Respondents' Perception and Attitude toward Community Pharmacists}

About $80 \%$ of respondents who had a positive perception of community pharmacists were found to also have a positive attitude toward community pharmacists. Consequently, the study found a significant and positive relationship between perception and attitude toward community pharmacists. The correlation coefficient for the relationship between perception and attitude was $r=0.71$, $p<0.01$.

Perception and Attitude toward Community Pharmacists in Saudi

\section{Community Pharmacists' Practices from the Public Perspective}

The third section in the questionnaire focused on the Saudi public's satisfaction with the community pharmacists' practices and the professional services they provided. The majority of the respondents recognized that community pharmacists were always available in community pharmacies when needed, treated their patients and visitors appropriately, answered their medical-related questions in a clear and understandable way, and provided their patients with sufficient explanation on how to use their medications. They also agreed, to a lower extent, however, with the pharmacists being open to offering health-related consultation with patients without being asked, advising the patient about any drug-drug or drugfood interaction, or educating patients about possible side effects that may occur with newly prescribed medications. Apart from these, the participants responded neutrally when asked if the community pharmacists usually enquired about their medical history and other medications they were currently using before dispensing any new medication, or about their medication regimen adherence when they went to collect a refill. The data from responses to questionnaire items concerning respondents' satisfaction with community pharmacists' practices and their professional services are summarized in Table 3 .

In a further investigation using the principal component analysis, 2 main components from 9 items in the third section of the questionnaire were identified. The first component included items 1, 2, 4, and 5, and these 
items reflected pharmacists' commitment and communication skills, with an overall median for these 4 items of 4 and an interquartile range of $4-5$. The second component included the remaining items (3, 6, 7, 8, and 9), and most of these items reflected the community pharmacists' ability to provide pharmaceutical care services, with an overall median of 3 of 5 and an interquartile range of 2-4. All the items, along with their medians and interquartile ranges, are presented in Table 3.

\section{Discussion}

The present study aimed to assess the current perception and attitude from the public toward pharmacists in the community setting in the KSA. The study found the majority of the respondents to have a positive perception of community pharmacists and their role in the community, with about two-thirds of respondents having a positive attitude toward them. Moreover, the study found a strong and positive relationship between the public's perception and attitude toward community pharmacists, but a positive attitude among the public was less frequently observed than a positive perception (69.8 vs. $81.4 \%$ ).

The majority of the pharmacists in the KSA at the time of the study were expatriates $(19,864$ expatriate pharmacists in total), which represented $81.4 \%$ of all registered pharmacists in the KSA. The majority of these expatriate pharmacists were practicing in community pharmacies and pharmaceutical companies and represented $98.7 \%$ of all pharmacists working in community pharmacies and $92.7 \%$ of all pharmacists in the pharmaceutical sector [12]. However, these numbers are expected to change in the next few years with the major transformation that the KSA is currently undergoing with the Saudi economic vision 2030. Therefore, the present study aimed to assess the current perception and attitude of the public toward community pharmacists with the aim of reassessing these measures in few years after we see the expected transformation in the pharmacy labor market in the KSA.

In general, the public's behaviors are affected by their perception of people, objects, and issues; however, the public's behaviors may be mediated by their attitude toward these things. Therefore, not all perceptions are translated into behaviors, as suggested by Dijksterhuis and Bargh [13]. While the majority of the respondents in the present study had an overall positive perception and attitude toward community pharmacists, they responded neutrally to the questionnaire item "I prefer speaking to a pharmacist before seeking a doctor's consultation." This describes how a positive perception and attitude from the public do not always translate into an overt behavior. Moreover, this finding is similar to that reported by Bawazir in another study that found pharmacists in the KSA to be the secondary source of information, after physicians [10].

Several studies have suggested the need to increase the knowledge and attitude toward medicines and pharmacists in the KSA $[14,15]$. Moreover, other countries from the Gulf Cooperation Council and the Middle East had similar community pharmacist-related concerns. In Kuwait, the public had some negative perceptions concerning community pharmacists [16], while in Lebanon, the public perception toward the community pharmacists still needs improvement [17]. Based on a recently published systematic review investigating the public attitudes toward community pharmacy in Arabic-speaking counties [18], the public had a low level of awareness of advanced pharmaceutical services that can be provided by community pharmacists.

Although the current study found a high level of satisfaction from the public with community pharmacists' commitment and communication skills (4 of 5), the level of satisfaction with the skills relevant to pharmaceutical care services was not, however, deemed satisfactory (3 of 5). This finding may reflect a low level of trust in community pharmacists' ability to provide such important clinical services. In Kuwait, Awad et al. found that community pharmacists had some overall negative perceptions with slightly positive community pharmacy services [16], which might conclude that the public might not be ready to accept pharmaceutical care services provided by community pharmacists yet. As the whole healthcare system in the KSA undergoes transformation, the role of community pharmacists is likely to increase significantly, raising the current level of satisfaction with and trust in the community pharmacists' ability to provide such services. This is of crucial importance before expanding the roles of pharmacists in the community setting in the future.

The findings of the study regarding the positive attitude toward community pharmacists are encouraging to further improve the pharmacy practice in the community pharmacy setting, to fulfill the major role that community pharmacies are expected to assume in the next era of the restructured healthcare system in the KSA. The practice in community pharmacy can be improved by expanding the space of permissible pharmaceutical care services in the community setting, which in turn will further improve the pharmacist's interpersonal skills $[19,20]$. This has already started in 2020 as the Ministry of Health has recently allowed pharmacists to provide more pharmaceutical
Almohammed/Alsanea 
care services in this setting, but the cost for these services could be a challenge in the beginning. Moreover, the positive attitude toward community pharmacists could be reflected on patients' adherence to their medication [21], and this can be assessed in future research. Besides, the relationship between community pharmacists and patients should be augmented as it could help identify and resolve medication-related problems and consequently improve the overall health system outcomes [22]. Community pharmacies, independently or in collaboration with the Ministry of Health, can invest in the positive relationship through providing a hotline or video call services to answer patients' health-related questions, particularly that the private consultation area is not always available in the community pharmacy setting and many health-related questions should be discussed in private. The impact of the new regulations that allow community pharmacies to provide more pharmaceutical care services on the public perception and attitude toward pharmacists in the community setting and the public acceptance to receive these services, either paid or as a complementary service, should be investigated in future research.

This study should be interpreted in light of the following limitations: data were collected from a convenience sample to investigate the current perception and attitude of the public toward community pharmacists; therefore, the findings may not be generalizable to the national level. Furthermore, the male-to-female ratio of participants (2.1:1) was not representative of the national gender distribution in the population (1:1), and the male gender of the researcher may have contributed to this study's limitation of male overrepresentation. Added to this, the distribution of the participants was skewed toward younger age-groups; therefore, the findings may not reflect the perception and attitude of older individuals. Likewise, the educational level of participants was skewed toward the highly educated from the overall population; thus, the findings should be interpreted in light of this limitation. However, the overrepresentation of younger individuals in the study can be considered a strength as the young will witness and participate in a growing capacity in the transformation of the KSA healthcare system currently taking place.

\section{Conclusion}

The KSA public's current positive perception and attitude toward community pharmacists, along with the high level of satisfaction with community pharmacists' commitment and communication, are encouraging. Thus, we can expect Saudi citizens to request and receive certain clinical services from community pharmacists such as medication therapy management, medication reconciliation, and management of chronic disease. However, the public's current low level of satisfaction with community pharmacists' ability to provide pharmaceutical care services is a major challenge to their role in the community and should be further investigated and addressed before more roles are assumed by pharmacists moving forward. Finally, as part of the systemic transformation that is already underway, extra effort and resources will need to be put into improving the community pharmacists' skills necessary for the new era of the Saudi health care.

\section{Acknowledgements}

The authors would like to thank the reviewers for their valuable comments and feedback. In addition, the authors acknowledge the contribution of Mohammed Fawaz Aloshaywi in this research. The authors also thank the Deanship of Scientific Research and Researchers Support and Services Unit at King Saud University for their technical support.

\section{Statement of Ethics}

Ethical approval for the research conduction and data collection was obtained from the Institutional Review Board at King Saud University Medical City (approval no. E-19-3665), and all participants consented to participate in the study.

\section{Conflict of Interest Statement}

The authors declare no conflict of interest.

\section{Author Contributions}

O.A. designed the study, collected and analyzed the data, and participated in the manuscript writing. S.A. contributed in the interpretation of the data and writing and revising the manuscript.

\section{Availability of Data and Materials}

The datasets generated and/or analyzed during the current study are not publicly available but are available from the corresponding author on reasonable request.
Perception and Attitude toward

Community Pharmacists in Saudi
Saudi J Health Syst Res 2021;1:67-74 DOI: 10.1159/000515207 


\section{References}

1 Saudi Ministry of Health. Implementing regulations of the pharmaceutical establishments and pharmaceuticals regulation: Saudi Minstry of Health. 2019. Available from: https:// www.moh.gov.sa/Ministry/Rules/Documents/051.pdf.

2 Alamari B, Aljasir B, Habadi M. Assessing the level of health literacy among adult visitors in the primary health care sitting of national guard health affair, Jeddah, Saudi Arabia. IJIR. 2017;3:645-54.

3 Alkhaldi TM, Al-Jumaili AA, Alnemer KA, Alharbi K, Al-Akeel ES, Alharbi MM, et al. Measuring the health literacy level of Arabic speaking population in Saudi Arabia using translated health literacy instruments. Pharm Pract. 2018 Jul-Sept;16(3):1223.

4 Chipidza FE, Wallwork RS, Stern TA. Impact of the doctor-patient relationship. Prim Care Companion CNS Disord. 2015;17(5).

5 Ekenga V, Bailey-Wheeler J, Sarpong D, Hart T, Earls M. Patients' perception of community pharmacists as healthcare providers and willingness to participate in pharmacist services: a pilot study. J Pharm Health Serv Res. 2018;9:297-300.

6 Al Akshar S, Shamssain M, Metwaly Z. Pharmacists perceptions of community pharmacy practice in UAE: an overview. IOSRPHR. 2014;4:47-56.

7 Tsao NW, Khakban A, Gastonguay L, Li K, Lynd LD, Marra CA. Perceptions of British Columbia residents and their willingness to pay for medication management services provided by pharmacists. Can Pharm J. 2015; 148(5):263-73.
8 Chen $\mathrm{H}$, Ung COL, Chi P, Wu J, Tang D, Hu H. Consumers' perceptions about pharmaceutical care provided by community pharmacists in China in relation to over-the-counter drugs: a qualitative study. Inquiry. 2018 Jan-Dec;55.46958018793292.

9 Al-Arifi M. Patients' perception, views and satisfaction with pharmacists' role as health care provider in community pharmacy setting at Riyadh, Saudi Arabia. Saudi Pharm J. 2012;20(4):323-30.

10 Bawazir SA. Consumer attitudes towards community pharmacy services in Saudi Arabia. Int J Pharm Pract. 2004;12(2):83-9.

11 Rashidi Y, Vaniea K, Camp J. Understanding Saudis' privacy concerns when using WhatsApp. Usable Security and Privacy 2016 Conference; San Diego, United States. 2016.

12 AlRuthia Y, Alsenaidy MA, Alrabiah $\mathrm{HK}, \mathrm{Al}-$ Muhaisen A, Alshehri M. The status of licensed pharmacy workforce in Saudi Arabia: a 2030 economic vision perspective. Hum Resour Health. 2018;16(1):28.

13 Dijksterhuis A, Bargh JA. The perception-behavior expressway: automatic effects of social perception on social behavior. Adv Exp Soc Psychol. 2001;33 1-40. Academic Press.

14 Alhaddad MS, Abdallah QM, Alshakhsheer SM, Alosaimi SB, Althmali AR, Alahmari SA. General public knowledge, preferred dosage forms, and beliefs toward medicines in western Saudi Arabia. Saudi Med J. 2014;35(6): 578-84.
15 Alsuhebany N, Alfehaid L, Almodaimegh $\mathrm{H}$, Albekairy A, Alharbi S. Attitude and perception of physicians and nurses toward the role of clinical pharmacists in Riyadh, Saudi Arabia: a qualitative study. SAGE Open Nurs. 2019 Jan-Dec;5.2377960819889769.

16 Awad A, Al-Rasheedi A, Lemay J. Public perceptions, expectations and views of community pharmacy practice in Kuwait. Med Princ Pract. 2017;26:438-46.

17 Iskandar K, Hallit S, Raad EB, Droubi F, Layoun N, Salameh P. Community pharmacy in Lebanon: a societal perspective. Pharm Pract. 2017;15(2):893

18 El Hajj MS, Mekkawi R, Elkaffash R, Saleh R, El Awaisi A, Wilbur K. Public attitudes towards community pharmacy in Arabic speaking Middle Eastern countries: a systematic review. Res Social Adm Pharm. 2020.

19 Meyer JC, Schellack N, Stokes J, Lancaster R, Zeeman H, Defty D, et al. Ongoing initiatives to improve the quality and efficiency of medicine use within the public healthcare system in South Africa; a preliminary study. Front Pharmacol. 2017;8:751.

20 Melton BL, Lai Z. Review of community pharmacy services: what is being performed, and where are the opportunities for improvement? Integr Pharm Res Pract. 2017;6:79-89.

21 Du Pasquier S, Aslani P. Concordance-based adherence support service delivery: consumer perspectives. Pharm World Sci. 2008;30(6): 846-53.

22 Tan EC, Stewart K, Elliott RA, George J. Pharmacist consultations in general practice clinics: the pharmacists in practice study (PIPS). Res Social Adm Pharm. 2014;10(4):623-32. 